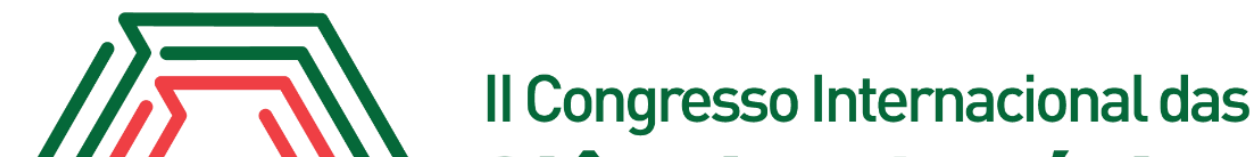 Ciências Agrárias COINTER - PDVAgro 2017
}

\section{PERCEPÇÃO AMBIENTAL DE USUÁRIOS DA PRAÇA PÚBLICA MIRIAM VASCONCELOS, NATAL - RN}

\author{
Apresentação: Pôster
}

Carmem Sara Pinheiro de Oliveira ${ }^{1}$; Cynthia Firmino Aires ${ }^{2}$; Heitor Barbosa de Morais Bittencourt Dutra ${ }^{3}$; José Custódio da Silva ${ }^{4}$; Fabíola Gomes de Carvalho ${ }^{5}$

\section{Introdução}

As áreas verdes urbanas assumem um importante papel na melhoria do ambiente e na oferta de espaços para lazer, recreação, atividades físicas e interação social, além de contribuírem para a sustentabilidade urbana. As praças desempenham importantes funções para a qualidade ambiental das cidades, uma vez que, promovem o equilíbrio do espaço urbano e natural. A necessidade do conhecimento da interação do ser humano com esse meio é fundamental para gerir melhores condições de vida à população.

Para o levantamento de dados, o trabalho foi realizado em um espaço público do município de Natal - RN, a Praça Miriam Vasconcelos, popularmente conhecido como "Praça do SESC", devido a sua localização estratégica, demanda por utilização de usuários de áreas próximas e sua importância histórica para os usuários residentes no conjunto Potilândia em Natal/RN. A justificativa da pesquisa se dá por meio da necessidade de melhor explorar as interações das pessoas que utilizam o espaço verde, visando o entendimento das suas necessidades, bem como sua relação com o meio. Portanto, o objetivo deste estudo foi apresentar a percepção ambiental de usuários acerca do contexto abrangente de usos múltiplos de espaços urbanos verdes, tendo como recorte a Praça Miriam Vasconcelos, Natal-RN.

\footnotetext{
${ }^{1}$ Mestra, Universidade Federal de Santa Catarina, carmem.sara@posgrad.ufsc.br

2 Pós-graduanda em Uso Sustentável de Recursos Naturais, Instituto Federal do Rio Grande do Norte, cynthia_aires@hotmail.com

${ }^{3}$ Pós-graduando em Gestão Ambiental, Instituto Federal do Rio Grande do Norte, heitor.br@gmail.com

${ }^{4}$ Pós-graduando em Gestão Ambiental, Instituto Federal do Rio Grande do Norte, custodio.biologia@yahoo.com.br

${ }^{5}$ Doutora, Instituto Federal do Rio Grande do Norte, fabiola.carvalho@ifrn.edu.br
} 


\section{Fundamentação Teórica}

Desde a antiguidade, as áreas verdes possuem diversas funções, tais como, conforto térmico, diminuição da poluição sonora, visual e do ar, abrigo para a fauna, etc. Além disso, esses espaços atuam como excelentes meios de qualidade de vida, pois estão ligados ao lazer, convívio social e recreação (NUCCI, 2008). Segundo Barros e Virgilio (2003), acerca desses espaços, a praça é um agente muito importante que exerce influência na melhoria da qualidade de vida da população e do meio ambiente urbano, pois reduz os efeitos causados pelo homem no processo de urbanização.

Apesar do conceito de qualidade ambiental urbana ser muito citado na literatura científica (BUCCHERI-FILHO e TONETTI, 2011), na prática ainda são incipientes as ações que são direcionadas para a melhoria das condições ambientais do espaço urbano, dentre elas a criação e a manutenção de áreas verdes públicas. Desse modo, as pesquisas nesta área são de suma importância para que possa ser melhor discutido o papel das áreas verdes no espaço urbano para a população em geral, assim como suas contribuições para a qualidade ambiental, permitindo assim reflexões na construção de ambientes mais saudáveis.

\section{Metodologia}

Para investigar a percepção ambiental dos sujeitos que utilizam o local de estudo (Praça Miriam Vasconcelos), foi realizada a aplicação in locu de questionários estruturados contendo 14 questões, onde foram analisados o tipo de uso, caracterização do ambiente e o perfil do usuário, no qual foram identificados apenas por idade, sexo e nível de escolaridade mantendo, assim, sua identidade preservada. Ao todo, 25 pessoas participaram da pesquisa que ocorreu durante o mês de setembro de 2017. Após a aplicação dos questionários, os mesmos foram analisados por meio de estatística descritiva no Excel e elaborado gráficos que representam a percepção sobre o estudo ambiental dos entrevistados.

\section{Resultados e Discussões}

Com esta pesquisa, foi possível perceber a utilização e a percepção, assim como os anseios, dos frequentadores da praça em questão. Participaram desta pesquisa 25 respondentes (16 mulheres e 9 homens), com idade variando de 13 a mais de 66 anos. A maioria dos usuários está situada na faixa etária de 36 a 65 anos (50\%), seguido por 19 a 35 (35\%), > 66 (10\%) e 13 a 18 (5\%). Os 
resultados mais expressivos na faixa etária de 36 a 65 anos justifica-se pelo fato de ser o conjunto Potilândia muito antigo, possuindo assim moradores de mais idade, enquanto os resultados percentuais de faixa etária inferior, justificam-se pela influência do grande fluxo de estudantes, sobretudo da Universidade Federal do Rio Grande do Norte que fica próxima ao local estudado.

Em relação ao nível de escolaridade dos entrevistados, foi encontrado um percentual de $40 \%$ com Ensino Superior Completo, 30\% Ensino Médio Completo, 10\% Ensino Fundamental Completo e Ensino Superior Incompleto (cada), 5\% Ensino Fundamental Incompleto e Ensino Médio Completo (cada), portanto todos os entrevistados possuem algum tipo de escolaridade, ainda que incompleto.

Quando questionados se eram moradores da região, 55\% afirmaram não ser, mas utilizam a praça para outros fins, tais como, percurso de trabalho (45\%), lazer e qualidade de vida (35\%) e trabalho e escola (20\%) cada. Vale ressaltar que além da UFRN, o SESC, que se localiza em frente à praça, possui uma escola de ensino básico o que também contribuiu para o elevado percentual obtido.

Com relação a frequência de visitação a essa área verde, foi observado que $45 \%$ dos entrevistados a visitam todos os dias, 35\% raramente, $10 \%$ de 2 a 3 vezes por semana e $10 \%$ uma vez por semana. Quando perguntados como eles classificavam a arborização da praça, $55 \%$ identificaram como razoavelmente arborizada, $25 \%$ afirmaram ser pouco arborizada e $20 \%$ disseram ser muito arborizada. Entretanto, o nível de consciência ambiental é melhor exposto quando abordados acerca da importância da arborização, no qual 100\% afirmam que acham importante arborizar os espaços verdes, pois segundo os entrevistados, isso acarretaria em diversos benefícios para a população.

Pode-se observar, de acordo com o Gráfico 1 que $80 \%$ das pessoas que participaram da pesquisa apontam a sombra como sendo um dos melhores benefícios da arborização, uma vez que, promove um ambiente propício para uso no período diurno.

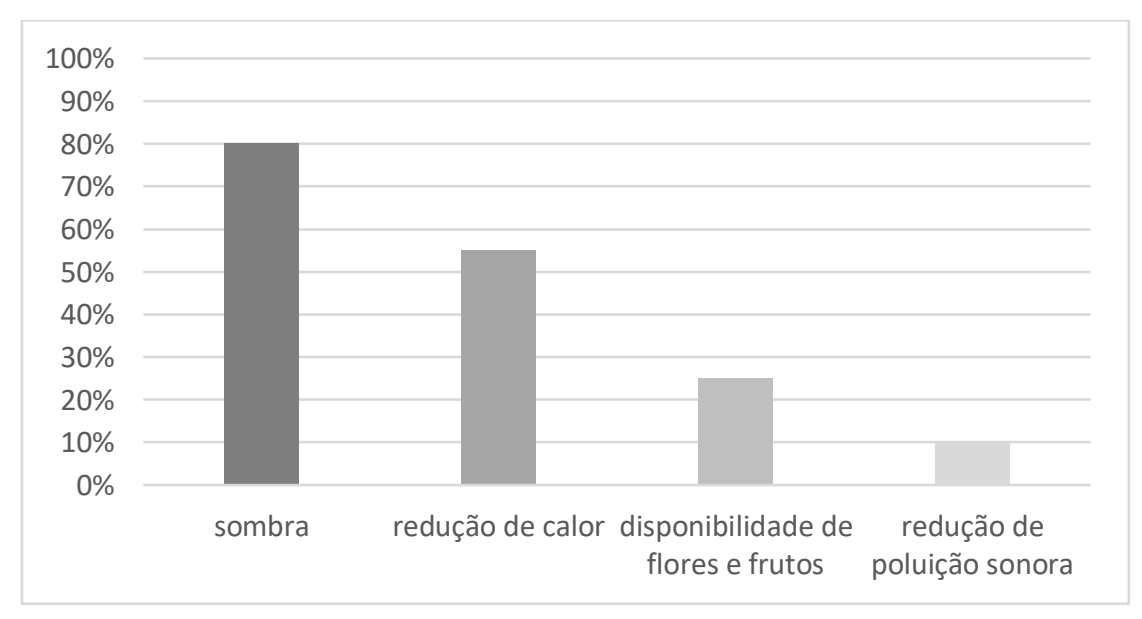

Gráfico 1: Fatores negativos da arborização. Fonte: Própria. 
Romero (1988), chama atenção para a importância dos planos de arborização urbana, recomendando que os mesmos devem observar as características da vegetação escolhida, pois sua eficácia e desempenho dependem diretamente delas, podendo responder corretamente ou não às exigências de permitir a insolação no inverno e produzir sombra no verão.

No que diz respeito aos fatores negativos da arborização, a sujeira das ruas e calçadas aparece com $80 \%$ de rejeição por parte dos usuários das praças, tendo em vista que, a mesma não possui uma manutenção por parte dos órgãos governamentais competentes, ficando a cargo de moradores e comerciantes a limpeza, causando desconforto e sensação de descaso com os usuários (Gráfico 2).

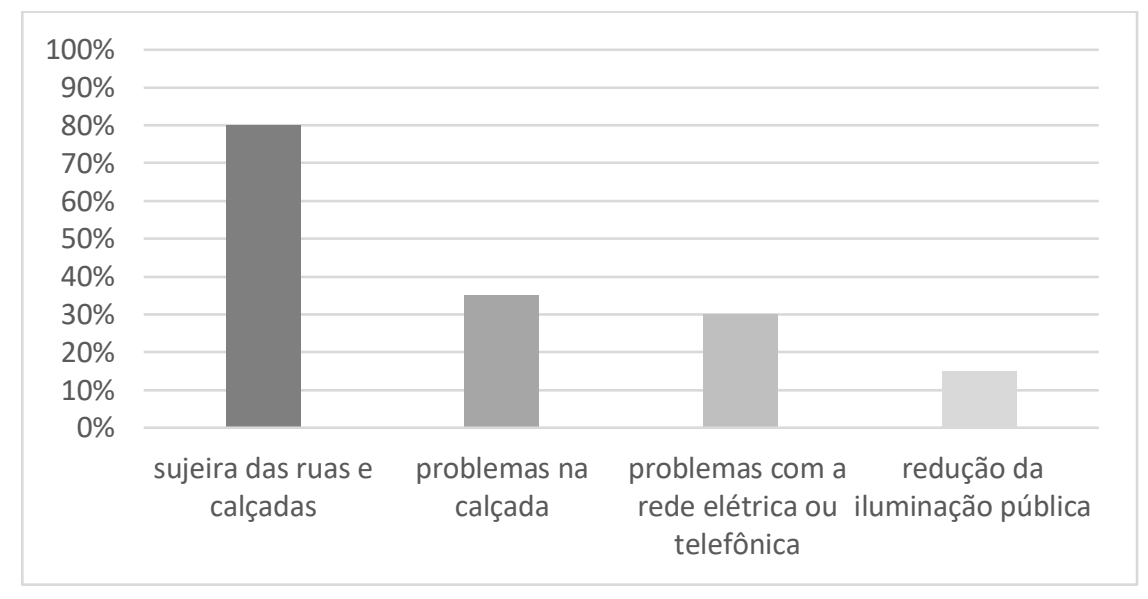

Gráfico 2: Fatores negativos da arborização. Fonte: Própria.

Segundo Bargos e Matias (2011), a manutenção das áreas verdes urbanas sempre foi justificada pelo seu potencial em propiciar qualidade ambiental à população, onde ela interfere diretamente na qualidade de vida dos seres por meio das funções sociais, ecológicas, estéticas e educativas, amenizando as consequências negativas da urbanização.

Quando indagados sobre que espécies de árvores consideram mais adequadas para serem plantadas em áreas verdes, os entrevistados responderam, quase que em sua totalidade (90\%), que espécies nativas são as indicadas. Em um estudo realizado por Silveira e Barros (2001), foi observado que que as praças públicas, se constituem como espaços verdes, normalmente compostos por vegetação exótica, que nem sempre está compatível com as exigências do público.

Já no que diz respeito as soluções e adequações para melhorar a arborização, os entrevistados assim responderam: fazer manutenção e realizar de forma adequada e em época correta as podas de formação (45\%), plantar mais árvores $(35 \%)$ e realizar um trabalho de conscientização ecológica sobre arborização (20\%). 
Adicionalmente, os sujeitos foram questionados se achavam que a poda das árvores era procedida de maneira correta, $60 \%$ respondeu que não e de maneira informal justificaram que as podas ocorrem em períodos muito longos e de maneira rápida. Para finalizar, os indivíduos responderam se apoiariam uma lei que criasse um imposto para incentivar o plantio e manutenção da arborização na cidade, $60 \%$ afirmou que não, justificando que já possuímos impostos demais, no qual parte do recurso deveria ser direcionado para a manutenção e principalmente arborização das praças públicas.

\section{Conclusões}

Ao analisar as informações, foi possível observar uma percepção positiva por parte dos entrevistados sobre a importância das áreas verdes na cidade. Em contrapartida, a praça em estudo encontra-se abandonada por parte do poder público, não assumindo a sua finalidade social, segundo a opinião dos frequentadores. Dessa forma, a relevância da manutenção e cuidados com as áreas verdes, além de contribuírem para uma harmonia paisagística do bairro, precisa ser atrativa na busca de usuários para o desenvolvimento de atividades de lazer, culturais e sociais, aumentando a qualidade de vida da população e, consequentemente, a consciência da preservação ambiental, por estarem assim, interligadas.

\section{Referências}

BARGOS, D.C.; MATIAS, L.F. Áreas verdes urbanas: um estudo de revisão e proposta conceitual. REVSBAU, Piracicaba - SP, v.6, n.3, p.172-188, 2011.

BARROS, M.V.F; VIRGILIO, H. Praças: espaços verdes na cidade de Londrina. Revista de Geografia, v.12, n.1, p. 533-544, 2003.

BUCCHERI-FILHO, A. T.; TONETTI, E. L. Qualidade ambiental nas paisagens urbanizadas. Revista Geografar. Curitiba: UFPR, v.6, n.1, p.23-54, jun./2011.

NUCCI, T. C. Qualidade Ambiental e Adensamento Urbano: um estudo de ecologia e planejamento da paisagem aplicada ao distrito de Santa Cecília (MSP). Curitiba: o autor, 2.ed, 150 p. 2008.

ROMERO, M. A. B. Princípios bioclimáticos para o desenho urbano. São Paulo: Projeto, 1988.

SILVEIRA, G.; BARros, M.V.F. Perfil Geoambiental de Praças: Região Norte da Cidade de Londrina-Pr. Revista Semina. Ed. da UEL, Londrina - PR, v. 22, p. 63-71, 2001. 